\title{
FORMAÇÃO DE PROFESSORES NA PERSPECTIVA DA EDUCAÇÃO INCLUSIVA: ANÁLISE DAS TESES PRODUZIDAS NO BRASIL ENTRE 2001 E 2011
}

\author{
TEACHERS' TRAINING IN PERSPECTIVE OF INCLUSIVE EDUCATION: AN ANALYSIS OF \\ THE THESES PRODUCED IN BRAZIL BERTWEEN 2001 AND 2011
}

\author{
Angela Meneghello Passos *, Sergio de Mello Arruda, Marinez Meneghello Passos ** \\ Instituto Federal do Paraná \\ E-mail: angela.passos@ifpr.edu.br \\ Universidade Estadual de Londrina \\ E-mail: sergioarruda@sercomtel.com.br, marinezmp@sercomtel.com.br
}

\section{Resumo}

Analisam-se as teses do banco de teses da Capes no período de 2001 a 2011 que abordaram a formação de professores (FP) na perspectiva da Educação inclusiva (EI). A partir de um corpus, encontrou-se que: (i) a maioria das teses abordou a FP diretamente; (ii) nas demais a FP consta apenas de forma marginal. A análise concentrou-se posteriormente nas teses classificadas em (i), das quais se pôde concluir que: poucos trabalhos estão voltados para a formação inicial de professores na perspectiva da El; a temática é importante para a formação continuada dos educadores, para que esses tenham acesso às novas tendências educacionais nessa perspectiva; há uma tendência para o desenvolvimento de reflexões sobre o processo inclusivo, o qual, de maneira discreta, já é uma temática sob investigação.

Palavras-chave: educação inclusiva. educação especial. formação de professores. banco de teses da Capes.

\begin{abstract}
In this paper we analyze the theses provided in the Capes database from 2001 to 2011 that addressed teacher education (TE) from the perspective of inclusive education (IE). From a corpus consisting of 50 theses, we find out that: (i) most of the theses (76\% of the corpus) is addressed to TE directly, either with an investigative purpose or as a result of the investigation, (ii) in the others $24 \%$ of the corpus TE appears only marginally, as subject in the theoretical assumptions, or in data analysis or as research background. The analysis focused subsequently on theses classified into (i), from which we concluded that: few studies are focused on initial teacher education in the perspective of IE; that the topic is important to the continued teachers training, because they may access the new educational trends in this perspective; there is a tendency to develop reflections on the inclusive process, which, in a discreet way, is already a thematic under investigation.
\end{abstract}

Keywords: inclusive education. special education. teachers' training. Capes thesis database. 


\section{INTRODUÇÃO}

Nos dias atuais ouvimos de maneira comum os termos era da informação e era digital, que buscam expressar o modelo atual de sociedade da maioria das nações. Este novo período das relações sociais humanas tem alterado desde a forma como as donas de casa trocam receitas culinárias até as formas de mobilização e articulação de manifestações populares. Não há um claro marco inicial dessa nova era, porém é bem definido seu momento de ascensão no fim da década de 1970 e início da década de 1980 com a difusão do microprocessador, das redes de computadores, da fibra óptica e do computador pessoal.

O que se produz no Brasil a respeito de formação de professores na perspectiva da Educação Inclusiva? Esta se constitui como pergunta de pesquisa para este momento, com a intenção de mostrar um panorama dessa situação em nosso país. Entre os caminhos a serem seguidos, para se ter uma noção da produção nacional a respeito de formação de professores na perspectiva da Educação Inclusiva, tem-se: artigos em revistas da área de educação especial, pedagogia, psicologia, educação, ensino; dissertações, teses, entre outros meios.

Como se pode notar, um universo bastante amplo de busca, e que foi preciso reduzir a fim de que os movimentos iniciais de uma investigação fossem exequíveis. Diante do exposto, e com a intenção de se ter um panorama do que é produzido no Brasil a respeito da formação de professores na perspectiva da Educação Inclusiva, concentramos esforços na análise do banco de teses da Capes - Coordenação de Aperfeiçoamento de Pessoal de Nível Superior.

A escolha pelas teses se deve ao fato de que elas representam um trabalho intelectual que divulga o resultado de uma investigação aprofundada, que revela a capacidade de seu autor em desenvolver investigações, ou seja, a tese é procurada "por aqueles que desejam se aperfeiçoar e especializar como pesquisadores científicos" (ECO, 2006, p.2), e que contribui para incrementar a área de estudo em questão. Entre os trabalhos científicos escritos, a tese é a que tem maior representatividade e consistência no meio acadêmico, por estar pautada em um rigor de argumentação, de apresentação de provas, de profundidade de ideias e de contribuição suficientemente original. 
Quando se fala em "descoberta", em especial no campo humanista, não cogitamos de invenções revolucionárias como a descoberta da fissão do átomo, a teoria da relatividade ou de uma vacina contra o câncer: podem ser descobertas mais modestas, considerando-se resultado científico até mesmo uma maneira nova de ler e entender um texto clássico, a identificação de um manuscrito que lança nova luz sobre a biografia de um autor, uma reorganização e releitura de estudos precedentes que conduzem à maturação e sistematização das ideias que se encontravam dispersas em outros textos. Em qualquer caso, o estudioso deve produzir um trabalho que, teoricamente, os outros estudiosos do ramo não deveriam ignorar, porquanto diz algo de novo sobre o assunto (ECO, 2006, p.2).

O banco de teses da Capes foi escolhido por ser de fácil acesso, por possuir uma ferramenta de busca e consulta que permite a pesquisa por assunto com o uso de palavras-chave e por disponibilizar teses de programas de pós-graduação de todo o Brasil.

A análise textual discursiva foi eleita nesta pesquisa como método de coleta e análise dos dados, para compreender o que está apresentado nas teses. A matéria-prima ou o corpus ${ }^{1}$ da análise textual é formado por documentos textuais, com imagens e outras expressões linguísticas. Estes documentos já podem estar à disposição do pesquisador, por exemplo: relatórios, publicações em jornais e revistas, resultado de avaliações, atas, dissertações, teses; ou ser produzidos especialmente para a pesquisa como entrevistas, depoimentos, registros de observações.

Pesquisas qualitativas têm se utilizado cada vez mais de análises textuais. Seja partindo de textos já existentes, seja produzindo o material de análise a partir de entrevistas e observações, a pesquisa qualitativa pretende aprofundar a compreensão dos fenômenos que investiga a partir de uma análise rigorosa e criteriosa desse tipo de informação. Não pretende testar hipóteses para comprová-las ou refutá-las ao final da pesquisa; a intenção é a compreensão, reconstruir conhecimentos existentes sobre os temas investigados (MORAES \& GALIAZZI, 2011, p.11).

\footnotetext{
${ }^{1} \mathrm{O}$ conjunto dos documentos tidos em conta para serem submetidos aos procedimentos analíticos (BARDIN, 2011,
} p.126). 
Conforme Moraes e Galiazzi (2011), o processo da análise textual discursiva inicia-se com a desmontagem dos textos, transformando-os em unidades elementares que destacam aspectos relevantes do tema analisado. Essa fragmentação dos textos conduz ao estabelecimento de relações entre essas unidades de base, ou seja, levam à construção de categorias que combinem unidades e expressem novos entendimentos. Essa categorização pode ocorrer de forma mais objetiva e dedutiva - a priori; ou de maneira mais subjetiva e indutiva - emergente.

As categorias constituídas formam a base da produção escrita que será produzida pelo pesquisador e que comunicará novas compreensões do fenômeno analisado. Essa construção de um novo emergente vai da descrição que expressa "de modo organizado os sentidos e significados construídos a partir das análises" (MORAES \& GALIAZZI, 2011, p.98), para a interpretação que revela ações mais profundas, em que o pesquisador procura correspondências com o aporte teórico que assumiu no início da pesquisa ou suas interpretações têm como base as teorias que emergem com as análises; e, por fim, essa produção escrita avança para a argumentação, em que o desafio se encontra em perceber além do que o discurso apresenta.

Essa metodologia

[...] pode ser compreendida como um processo auto-organizado de construção de compreensão em que novos entendimentos emergem a partir de uma sequência recursiva de três componentes: a desconstrução dos textos do "corpus", a unitarização; o estabelecimento de relações entre os elementos unitários, a categorização; o captar o emergente em que a nova compreensão é comunicada e validada (MORAES; GALIAZZI, 2011, p.12, grifo do autor).

\section{PROCEDIMENTO METODOLÓGICO E CONSTITUIÇÃO DO CORPUS}

Para iniciar a seleção das teses, precisava-se de um elemento de busca, também denominado na análise textual por unidade de busca. Essas unidades surgiram a partir do tema da investigação: realizou-se a busca das teses com as expressões educação especial e, na sequência, educação inclusiva. Essa busca ocorreu de novembro de 2012 a janeiro de 2013, no site de banco de teses da Capes, no endereço: http://www.capes.gov.br/servicos/banco-de-teses. 
A partir desta página inicial, acessa-se o link 'Resumos' e abre-se uma página onde é possível fazer a busca desejada. Para esta investigação não foi indicado autor e nem instituição; em assunto, em um primeiro momento, foi incluída a expressão exata educação especial e, em um segundo momento, a expressão exata educação inclusiva; essas unidades de busca surgiram a partir do objetivo primário que possuímos. No item nível selecionou-se doutorado e os anos-bases foram de 2001 a 2011. Como a busca e a montagem do corpus foi iniciada em 2012, limitou-se o ano-base até 20112.

A concentração de esforços para selecionar as teses deste milênio deve-se ao fato de que o processo de uma Educação Inclusiva iniciou-se na última década do século passado, em que convenções mundiais e legislações nacionais influenciaram a elaboração de políticas de inclusão educacional e, além disso, como se pode ver no quadro a seguir, o número de teses nessa área é bem reduzido no início do milênio. Tal constatação também se deve à novidade desse campo investigativo nas academias científicas.

A expressão exata educação especial foi encontrada em 229 teses e, a expressão exata educação inclusiva em 106, distribuídas conforme o quadro a seguir.

Quadro 1. Distribuição das teses encontradas a partir das expressões exatas Educação especial e Educação inclusiva de 2001 a 2011.

\begin{tabular}{|r|c|c|c|c|c|c|c|c|c|c|c|}
\hline $\begin{array}{r}\text { Ano } \\
\text { Expressã̃ }\end{array}$ & 2011 & 2010 & 2009 & 2008 & 2007 & 2006 & 2005 & 2004 & 2003 & 2002 & 2001 \\
\hline $\begin{array}{c}\text { Educação } \\
\text { especial }\end{array}$ & 29 & 32 & 29 & 24 & 29 & 21 & 25 & 15 & 9 & 11 & 5 \\
\hline $\begin{array}{c}\text { Educação } \\
\text { inclusiva }\end{array}$ & 20 & 11 & 16 & 11 & 12 & 10 & 11 & 8 & 2 & 4 & 1 \\
\hline
\end{tabular}

Fonte: dados da pesquisa.

\footnotetext{
${ }^{2}$ Como o processo de busca do site de banco de teses da Capes sofreu mudanças após o período de coleta, os dados referentes às teses de 2012 e 2013 não foram atualizados. Acredita-se que a visão que o período de 2001 a 2011 proporcionou a respeito do tema em questão é expressiva e que a atualização não acarrete alterações significativas na leitura realizada com os dados coletados, todavia venha corroborar com o que está posto.
} 
Os números mostram que a produção na área aumentou com o passar dos anos e que a expressão educação especial é a mais utilizada entre os pesquisadores. Talvez isso se deva à mudança de concepção, percepção que a expressão Educação Inclusiva carrega em sua conceituação e que ainda é recente, fato esse que corrobora com a opção de concentrar esforços na seleção de teses desse milênio.

Detectamos que nessa fase do levantamento, algumas teses foram selecionadas tanto na busca por meio da expressão exata educação especial, como quando fizemos uso da expressão exata educação inclusiva; portanto, teve-se o cuidado de excluir essa tese da segunda lista em organização, criando um código para destacar essa repetição com relação ao primeiro levantamento, a fim de que esse destaque não se perdesse e pudesse cooperar com possíveis interpretações.

Ao abrir cada uma das teses encontradas pelo sistema de busca do site, é possível observar várias informações a respeito do trabalho de doutorado. Em virtude dessa quantidade de dados, iniciouse uma seleção mais focada no objetivo de extrair desse acervo de teses as que traziam no título, palavras-chave, linha de pesquisa e resumo, algo relacionado à formação de professores, tema desta investigação: Educação Inclusiva e a formação de professores. Por conseguinte, realizou-se um novo movimento, em que a unidade de busca passou a ser a palavra formação vinculada à formação de professores, à formação docente. Para esta fase utilizou-se a ferramenta 'Localizar' . Logicamente que esse termo foi destacado em meio às palavras 'transformação' e 'informação', que foram descartadas por não fazerem parte do contexto da investigação, assim como o termo formação vinculado a contextos diferentes da formação profissional do educador, por exemplo, com foco na formação do educando ou dos gestores das instituições de ensino.

Desse modo, o acervo sofreu uma redução no número de teses para análise, perfazendo um total de 59 teses, sendo 38 teses relacionadas à expressão educação especial e 21 relacionadas à expressão educação inclusiva.

Essas 59 teses passaram por um processo denominado 'leitura flutuante' e percebeu-se que uma das teses foi selecionada somente pelo título, verificando-se, após a leitura do resumo que, mesmo não constando a palavra formação seu conteúdo tratava de capacitação docente, 
permanecendo a tese no acervo. O mesmo não aconteceu com sete teses que trazem somente no item linha de pesquisa, expressões como: formação de professores, formação docente, formação de profissionais da educação. Mesmo a linha de pesquisa destacando essas expressões, o contexto da investigação desenvolvida por seus autores foca outros temas, entre eles: questões históricas, sociais, culturais e políticas; currículo escolar e projeto político pedagógico; tecnologia assistiva. Permanecendo no acervo 52 teses para o procedimento analítico.

Outras duas teses foram selecionadas somente pelas palavras-chave, sendo preciso uma leitura cautelosa de seu resumo e outras seções para identificar se essa formação estava relacionada com a formação docente. Pelo resumo verificou-se que uma das teses tratava da formação de professores, mas com ênfase em classes de aceleração e de alunos com dificuldades de aprendizagem. A outra focava na percepção dos professores quanto às adaptações arquitetônicas, de material didático, nos projetos pedagógicos, que são necessárias para o processo de inclusão social. Portanto, as duas foram retiradas, permanecendo no acervo constituído 50 teses, que estão relacionadas no ANEXO A.

Nesse caminho traçado e observando as teses selecionadas, o que se pode notar é que, independente do termo formação aparecer no título, nas palavras-chave ou na linha de pesquisa, o que vai confirmar se essa formação está relacionada com a formação docente é o conteúdo encontrado no resumo. Desta forma, pode-se concluir que as 50 teses, que agora compõem o corpus desta investigação, destacam em seus resumos a formação de professores.

Quadro 2. Distribuição das teses que compõem o corpus de 2001 a 2011.

\begin{tabular}{|r|c|c|c|c|c|c|c|c|c|c|c|c|}
\hline $\begin{array}{r}\text { Ano } \\
\text { Expressãa }\end{array}$ & 2011 & 2010 & 2009 & 2008 & 2007 & 2006 & 2005 & 2004 & 2003 & 2002 & 2001 & Total \\
\hline $\begin{array}{c}\text { Educação } \\
\text { especial }\end{array}$ & 3 & 3 & 4 & 1 & 1 & 1 & 2 & 3 & 0 & 1 & 1 & $\mathbf{2 0}$ \\
\hline $\begin{array}{c}\text { Educação } \\
\text { inclusiva }\end{array}$ & 3 & 1 & 7 & 3 & 1 & 0 & 2 & 0 & 0 & 0 & 0 & $\mathbf{1 7}$ \\
\hline $\begin{array}{c}\text { As duas } \\
\text { expressões }\end{array}$ & 3 & 2 & 2 & 0 & 2 & 2 & 1 & 0 & 0 & 1 & 0 & 13 \\
\hline Total & 9 & 6 & 13 & 4 & 4 & 3 & 5 & 3 & 0 & 2 & 1 & $\mathbf{5 0}$ \\
\hline
\end{tabular}

Fonte: dados da pesquisa. 
Por meio de um olhar quantitativo percebe-se que nesse milênio ocorreu um aumento nas produções científicas a respeito da formação de professores na Educação Especial e/ou na perspectiva da Educação Inclusiva, mas esta produção ainda é pequena quantitativamente e, pela atualidade do tema, há muito que se pesquisar nesse campo ${ }^{3}$ investigativo.

Em Bardin (2011, pp.126-128) tem-se que a constituição do corpus requer escolhas, seleções e regras; e que as principais regras são: regra da exaustividade, regra da representatividade, regra da homogeneidade e regra da pertinência. No corpus construído levaram-se em conta as regras indicadas por Bardin: em relação à exaustividade - foram observadas todas as teses; de acordo com a representatividade - não se trabalhou com uma amostra, analisaram-se todas as teses selecionadas; em concordância com a homogeneidade - todas as teses foram escolhidas por um único pesquisador, com base nos mesmos critérios de escolha; segundo a pertinência - as teses que compõem o corpus estão correlacionadas aos objetivos da pesquisa.

O método de estudo de caso consiste na instrução pelo uso de narrativas sobre indivíduos enfrentando decisões ou dilemas contidos em determinadas situações. Colocado no cenário da narrativa, o aluno é incentivado, sobretudo, a ler, a se familiarizar com personagens, a compreender fatos, valores e contextos visando uma solução, que de modo geral, não é a única. Embora a adoção do método no ensino de ciências não seja igualmente comum quanto em áreas como medicina, direito, economia e engenharia, há, segundo Sá e Queiroz (2009), nos últimos anos um incremento no número de trabalhos reportados por professores de Física, Química e Biologia em revista da área de educação em Ciências.

No que diz respeito à produção de estudos de caso, Herreid (1998) estabelece diretrizes para se criar um "bom estudo de caso". Segundo o autor, o "bom estudo de caso" narra uma história, desperta o interesse pela questão, é atual, produz empatia com os personagens centrais, inclui citações, é relevante ao leitor, tem utilidade pedagógica, provoca um conflito, força uma decisão e faz generalizações.

\footnotetext{
${ }^{3}$ Considera-se o termo campo como 'área em que se desenvolve alguma atividade', neste caso, pesquisas e/ou projetos relativos à formação de professores na perspectiva da Educação especial e/ou inclusiva.
} 
Nos estudos de caso pesa o caráter coletivo e cooperativo que passa a ser incentivado e desenvolvido como uma habilidade social e do trabalho profissional, considerando as mais prováveis inserções de cada aluno no mundo do trabalho. Quando se utiliza um estudo de caso, o professor deve prever tarefas individuais e coletivas, aulas em sala e em laboratórios, ampliar os momentos de discussões de leituras científicas (Herreid, 1994). Tudo isso, favorece a curiosidade, o desejo de continuar interagindo, de identificar problemas, de pesquisar informações, de questionar e confrontar resultados e de propor soluções de problemas.

Com relação aos tipos de estudos de caso empregados no ensino de Ciências, quatro se destacam na literatura: os estudos de caso científicos e sócio-científicos (Sá e Queiroz, 2009), os estudos de caso históricos (Stinner et al., 2003) e os estudos de caso de ensino (Merseth, 1996). Cada um deles é voltado para um contexto formativo específico.

\section{RESULTADOS E DISCUSSÃO}

Apesar de o Quadro 2 trazer as teses organizadas em três grupos, de acordo com a expressão exata de busca, para a etapa investigativa que se segue, as 50 teses foram reunidas em um único agrupamento.

Nessa etapa foi realizada a leitura integral dos resumos e quando necessário algumas outras seções e uma diversidade de olhares foi lançada sobre o corpus. A partir desses olhares ocorreu um avanço na análise das teses, das quais emergiram as seguintes categorias:

1. Propósito. As teses selecionadas nesta categoria têm a formação de professores como objetivo investigativo. Entre esses objetivos encontram-se: as ações de analisar, conhecer, refletir, tecer críticas, investigar, acompanhar, contribuir, destacar a importância, realizar uma leitura, compreender, discutir as políticas, buscar uma compreensão - voltadas para a formação de professores na Educação Especial e/ou na perspectiva da Educação Inclusiva.

2. Dedução. Nas teses destacadas nesta categoria a formação de professores encontra-se, como consequência da investigação, nas evidências ao final do processo investigativo. Entre esses resultados tem-se: direcionamentos, encaminhamentos de novas pesquisas, sinalizações, 
transformações, debates, discussões, reavaliações, novas formas de pensar, novas perspectivas, investimentos, incentivos - voltados para a formação de professores na Educação especial e/ou na perspectiva da Educação Inclusiva.

3. Referencial teórico. Nas teses que compõem esta categoria depara-se com a formação de professores entre as temáticas dos pressupostos teóricos que sustentam, embasam as investigações.

4. Análise. Nas teses selecionadas nesta categoria a formação de professores aparece no momento da análise dos dados, destacando leituras de textos, posicionamentos, identificações, influências, princípios - voltados para a formação de professores na Educação Especial e/ou na perspectiva da Educação Inclusiva.

5. Panorama. As teses destacadas nesta categoria possuem a formação de professores como pano de fundo no qual se realiza a pesquisa. Os cursos de formação docente, a falta de preparação do professor em sua formação inicial e continuada, a formação contínua na perspectiva inclusiva, tornaram-se uma justificativa para a ação investigativa.

As teses que compõem o corpus ficaram assim distribuídas nas categorias emergentes.

Quadro 3. Distribuição das teses nas categorias emergentes.

\begin{tabular}{|c|c|c|c|c|c|}
\hline Categorias & Propósito & Dedução & $\begin{array}{c}\text { Referencial } \\
\text { teórico }\end{array}$ & Análise & Panorama \\
\hline $\begin{array}{c}\text { Número de } \\
\text { teses }\end{array}$ & 20 & 18 & 4 & 5 & 3 \\
\hline
\end{tabular}

Fonte: dados da pesquisa.

Em síntese, o Quadro 3 mostra que $76 \%$ das teses selecionadas para o corpus abordam diretamente a formação de professores, enquanto que nas demais ( $24 \%$ do corpus) essa temática é abordada apenas marginalmente.

Com essas categorias pode-se caracterizar, a partir das teses analisadas e de forma resumida, que entre as pesquisas a respeito da formação de professores na Educação Especial e/ou na perspectiva da Educação Inclusiva, tem-se: as que focam na formação de professores como objetivo de suas investigações; as que fazem considerações a respeito do tema a partir dos 
resultados encontrados; existem também as que tratam da formação de professores no aporte teórico que as sustentam; bem como as que na análise dos dados destacam o tema; e, para finalizar, as que se desenvolvem tendo como panorama a formação de professores.

Estamos cientes de que o desenvolvimento metodológico utilizado para a coleta de dados pode ter deixado de lado algumas teses, todavia, acredita-se que as selecionadas contribuíram para a compreensão do que se buscava.

A partir de um novo olhar sobre o corpus, tratar-se-á a expressão 'formação de professores na Educação Especial e/ou na perspectiva da Educação Inclusiva' somente por 'formação de professores na Educação Inclusiva'. Não se fará mais essa diferenciação da formação de professores na Educação Especial e na Educação Inclusiva. Como o objetivo dessa investigação é tratar da formação de professores na Educação Inclusiva, mesmo os trabalhos que focaram seus esforços na Educação Especial serão incorporados como subsídios da formação de professores na Educação Inclusiva.

Nessa etapa, o estudo em desenvolvimento volta-se para as categorias Propósito e Dedução, em que há uma maior concentração de teses; no total, 38 ; ou seja, $76 \%$ das teses. As demais categorias tratam da formação de professores como temática para os pressupostos teóricos, em leituras complementares para análise dos dados, como justificativa da ação investigativa e não como origem, fato, causa e nem como consequência, resultado, conclusão da pesquisa, por isso foram descartadas desse novo olhar.

Realizando uma releitura dos documentos, verifica-se que tanto na categoria Propósito como na Dedução, os textos dão maior ênfase à formação continuada de professores, assim novas categorias ou subcategorias emergem a partir dos documentos avaliados.

Para a categoria Propósito, as subcategorias encontradas são:

1. Formação continuada (FCP - formação continuada na categoria propósito). Nos documentos desta subcategoria encontram-se aqueles que investigam uma experiência formativa, uma pesquisa-ação, um programa desenvolvido a distância (via internet), cursos de especialização, uma pesquisa-formação, uma pesquisa-intervenção; outros que discutem as políticas públicas de 
formação do professor; como também os que analisam movimentos, aspectos e percursos do processo de formação docente e os que destacam a importância da formação continuada dos educadores.

2. Formação inicial (FIP - formação inicial na categoria propósito). Nesta subcategoria percebe-se que as pesquisas estão relacionadas à análise de cursos de Pedagogia e de Educação Física, na perspectiva inclusiva.

3. Formação geral (inicial e continuada) (FGP - formação geral na categoria propósito). Nas teses selecionadas nesta subcategoria depara-se com uma análise geral da formação de professores enfatizando ambas ou não especificando o tipo de formação: inicial ou continuada. O panorama dessas investigações está em documentos nacionais e internacionais, referenciais teóricos, políticas públicas, redes de pesquisa.

Para a categoria Dedução, as subcategorias encontradas possuem os mesmos nomes que as apresentadas para a categoria propósito.

1. Formação continuada (FCD - formação continuada na categoria dedução). Nos documentos desta subcategoria encontram-se os que ressaltam nas considerações a incorporação de estudos sobre atitudes, o trabalho com mobilidade, construção de novos significados, um olhar mais pedagógico e menos técnico, a viabilidade de um trabalho colaborativo; outros apontam a importância de reflexões, transformações, novas pesquisas, novas contribuições, organização de espaços e tempos, repensar currículos, modificações de conceitos; e ainda aqueles que destacam a complexidade do processo inclusivo.

2. Formação inicial (FID - formação inicial na categoria dedução). Nesta subcategoria percebe-se que as pesquisas salientam o valor de se repensar cursos e estabelecer relações com as necessidades da sociedade.

3. Formação geral (inicial e continuada) (FGD - formação geral na categoria dedução). Nas teses selecionadas nesta subcategoria depara-se com uma análise geral da formação de professores enfatizando ambas ou não especificando o tipo de formação: inicial ou continuada. O panorama dessas investigações está na viabilidade de um trabalho colaborativo, na complexidade do processo inclusivo, no estudo de novas ações, no processo de construção do saber-fazer pedagógico, no debate de novas políticas e na valia de reflexões e discussões. 
Quadro 4. Distribuição das teses nas subcategorias indicadas.

\begin{tabular}{|c|c|c|}
\hline Categorias & Propósito & Dedução \\
\hline $\begin{array}{c}\text { Formação } \\
\text { continuada }\end{array}$ & 13 & 10 \\
\hline Formação inicial & 4 & 2 \\
\hline Formação geral & 3 & 6 \\
\hline
\end{tabular}

Fonte: dados da pesquisa.

Entre as várias ponderações que se pode realizar a partir do exposto, relaciona-se a seguir as subcategorias de mesmo nome.

Uma correspondência entre FCD (formação continuada na categoria dedução) e FCP (formação continuada na categoria propósito) é apresentada no quadro abaixo.

\begin{tabular}{|c|c|}
\hline FCD preconiza... & FCP desenvolve... \\
\hline $\begin{array}{l}\text {...estudos sobre atitudes, construção de } \\
\text { novos significados, modificações de } \\
\text { conceitos; } \\
\text {...a importância de reflexões, } \\
\text { transformações, novas pesquisas, novas } \\
\text { contribuições. }\end{array}$ & $\begin{array}{l}\text {...investigação de experiência formativa, } \\
\text { pesquisa-ação, programa desenvolvido a } \\
\text { distância (via internet), cursos de } \\
\text { especialização, pesquisa-formação, } \\
\text { pesquisa-intervenção, políticas públicas, } \\
\text { movimentos educacionais, aspectos e } \\
\text { percursos do processo de formação } \\
\text { docente. }\end{array}$ \\
\hline
\end{tabular}

Percebe-se um movimento de levantamento de necessidades que surgem em FCD e que em FCP estão sendo trabalhadas, ou seja, alguns pesquisadores preconizam faltas, lacunas e outros, com suas investigações, contribuem para o preenchimento dos espaços em aberto. Talvez não com a intensidade a qual o momento exige - construção de uma sociedade inclusiva - contudo já existem pesquisas para atender essa demanda. Desse modo, os esforços vêm ao encontro dos trabalhos que destacam a importância da formação continuada dos educadores, para que esses tenham acesso às novas tendências educacionais na perspectiva inclusiva.

Outra correspondência é a que relaciona FID (formação inicial na categoria dedução) e FIP (formação inicial na categoria propósito). 


\begin{tabular}{|l|ll|}
\hline \multicolumn{1}{|c|}{ FID salienta... } & \multicolumn{1}{|c|}{ FIP realiza... } \\
\hline $\begin{array}{l}\text {...a precisão de se repensar cursos; } \\
\text {...o estabelecimento de relações com as } \\
\text { necessidades da sociedade. }\end{array}$ & ...análises de cursos: Pedagogia e & \\
& Educação física. & \\
\hline
\end{tabular}

A partir do levantamento realizado verifica-se que ainda são poucos os trabalhos voltados para a formação inicial de professores na perspectiva da Educação inclusiva, é preciso investigar ainda mais os cursos indicados e outros cursos de Licenciatura. Vê-se aqui uma grande lacuna, ou seja, um campo investigativo bastante amplo a ser explorado.

Outra correspondência é a que relaciona FGD (formação geral na categoria dedução) e FGP (formação geral na categoria propósito).

\begin{tabular}{|c|c|}
\hline FGD destaca... & FGP analisa... \\
\hline $\begin{array}{l}\text {...a viabilidade de um trabalho } \\
\text { colaborativo, a complexidade do processo } \\
\text { inclusivo, o estudo de novas ações, a } \\
\text { construção do saber-fazer pedagógico, o } \\
\text { debate de novas políticas, a importância } \\
\text { de reflexões e discussões. }\end{array}$ & $\begin{array}{l}\text {...documentos nacionais e internacionais, } \\
\text { referenciais teóricos, políticas públicas, } \\
\text { redes de pesquisa. }\end{array}$ \\
\hline
\end{tabular}

Como na correspondência entre $F C D$ e $F C P$, neste último quadro também se encontra um movimento de levantamento de necessidades e a realização de trabalhos para preencher as lacunas. Observa-se que em FGD há uma sinalização para estudos, debates, reflexões, discussões sobre o complexo processo inclusivo, e que, de maneira acanhada, já está em análise em FGP. Igualmente nas outras relações encontram-se lacunas que precisam ser preenchidas com novas investigações. 


\section{CONSIDERAÇÕES FINAIS}

Nestas considerações destaca-se a questão dessa pesquisa: O que se produz no Brasil a respeito de formação de professores na perspectiva da Educação Inclusiva? Para responder a essa pergunta, foram selecionadas teses do banco de teses da Capes e a análise textual discursiva foi eleita como método de coleta e análise dos dados.

Desse processo destacou-se 50 teses que constituíram o corpus desta investigação. Decorrente dessas teses, cinco categorias foram construídas e percebe-se que os significados do tema pesquisado na configuração das teses analisadas resumem-se nessas cinco categorias, isto é, o tema está relacionado com os objetivos investigativos - categoria propósito; as evidências ao final do processo de investigação - categoria dedução; as temáticas dos pressupostos teóricos categoria pressuposto teórico; os subsídios utilizados na análise dos dados - categoria análise; e com o cenário ao qual se realiza a pesquisa - categoria panorama.

Um novo olhar foi lançado nas categorias propósito e dedução, por concentrarem em si um maior número de teses. Em ambas, emergiram três subcategorias de mesmo nome, mas com focos diferenciados; são elas: formação continuada, formação inicial e formação geral.

Percebe-se um movimento de levantamento de necessidades que surgem na subcategoria formação continuada da categoria dedução (FCD) e que na subcategoria formação continuada da categoria propósito (FCP) estão sendo trabalhadas, ou seja, alguns pesquisadores preconizam faltas, lacunas e outros, com suas investigações, contribuem para o preenchimento dos espaços em aberto. A subcategoria formação inicial da categoria dedução (FID) salienta a precisão de se repensar cursos e o estabelecimento de relações com as necessidades da sociedade, já a subcategoria formação inicial da categoria propósito (FIP) realiza análises de cursos. Observa-se que na subcategoria formação geral da categoria dedução (FGD) há uma sinalização para estudos, debates, reflexões, discussões sobre o complexo processo inclusivo, e que, de maneira acanhada, já está em análise na subcategoria formação geral da categoria propósito (FGP).

Por meio de um olhar quantitativo percebeu-se que nesse milênio ocorreu um aumento nas produções científicas a respeito da formação de professores na perspectiva da Educação Inclusiva, 
mas esta produção ainda é pequena quantitativamente e, pela atualidade do tema, há muito que se pesquisar nesse campo investigativo. O que é confirmado pela análise qualitativa do corpus construído, onde lacunas em aberto precisam ser preenchidas com novas investigações.

Por fim, este estudo mostra que a inclusão é um processo complexo e polêmico, por isso mesmo necessita ser mais debatido e compreendido por todos os responsáveis por seu planejamento, execução e acompanhamento, pois, embora já venha sendo estudado há algum tempo, ainda resta muito a ser realizado. Nessa perspectiva aponta a formação dos professores, inicial e continuada, como um dos requisitos essenciais para que a inclusão escolar de alunos com deficiências visuais, nessa pesquisa em particular, e de outros estudantes na condição de outras deficiências, e sem deficiências, alcance o sucesso desejado, tendo em vista que a escola inclusiva configura um novo espaço educativo, didático, curricular, organizativo e institucional e por isso exige uma formação que parta do desenvolvimento de atitudes próprias a profissionais reflexivos (BEZERRA, 2011, resumo).

\section{REFERÊNCIAS}

BARDIN, Laurence. Análise de conteúdo. Tradução de Luís Antero Reto, Augusto Pinheiro. São Paulo: Edições 70, 2011.

BEZERRA, Maria de Lourdes Esteves. Inclusão de pessoas com deficiência visual na escola regular: bases organizativas e pedagógicas no estado do Acre. 2011. 256p. Tese (Doutorado em Educação) Universidade Federal de Minas Gerais, Belo Horizonte, 2011. Disponível em: <http://capesdw.capes.gov.br/capesdw/resumo.html?idese=20111632001010001P7>. Acesso em: 24 ago. 2013.

ECO, Umberto. Como se faz uma tese. Tradução de Gilson Cesar Cardoso de Souza. São Paulo: Perspectiva, 2006.

MORAES, Roque; GALIAZZI, Maria do Carmo. Análise textual discursiva. Ijuí: Unijuí, 2011. 


\section{ANEXO A}

\section{Relação das $\mathbf{5 0}$ teses que fazem parte do corpus em estudo.}

Informações retiradas do banco de teses da Capes. Disponível em:

http://capesdw.capes.gov.br/capesdw/

Acesso em: nov. 2012 a jan. 2013.

Em cada seleção, as teses encontram-se em ordem cronológica crescente; em um mesmo ano, em ordem alfabética pelo nome do autor.

\section{Teses selecionadas a partir da expressão exata educação especial.}

1. Nely Garcia. Programas de orientação e mobilidade no processo de educação da criança portadora de deficiência. 01/05/2001

1v. 212 p. Doutorado. UNIVERSIDADE DE SÃO PAULO - EDUCAÇÃO

Orientador(es): Newton Kara Jose

Biblioteca Depositária: FEUSP

2. Ivanilde Apoluceno de Oliveira. Saberes imaginários e representações na construção do saberfazer-educativo de professores/as na educação especial. 01/04/2002

3v. 222p. Doutorado. PONTIFÍCIA UNIVERSIDADE CATÓLICA DE SÃO PAULO - educação (currículo)

Orientador(es): Alipio Márcio Dias Casali

Biblioteca Depositária: Biblioteca Central Nadir Kfouri

3. Maria Helena Michels. A formação de professores de educação especial na UFSC (1998-2001): ambiguidades estruturais e a reiteração do modelo médico-psicológico. 01/07/2004

1v. 169p. Doutorado. PONTIFÍCIA UNIVERSIDADE CATÓLICA DE SÃO PAULO - educação: história, política, sociedade

Orientador(es): José Geraldo Silveira Bueno

Biblioteca Depositária: PUC-SP

4. Marines Saraiva Carlota. A deficiência como fenômeno social: categorias, rótulos, e suas influências na estruturação conceptual e na ação do professor. 01/04/2004

1v. 175p. Doutorado. UNIVERSIDADE DE SÃO PAULO - EDUCAÇÃO

Orientador(es): Ida Lichtig

Biblioteca Depositária: FEUSP

5. Rosalba Maria Cardoso Garcia. Políticas públicas de inclusão: uma análise no campo da educação especial brasileira. 01/02/2004

1v. 216p. Doutorado. UNIVERSIDADE FEDERAL DE SANTA CATARINA - EDUCAÇÃO

Orientador(es): Eneida Oto Shiroma

Biblioteca Depositária: B.U.

6. Patrícia Maria Fragelli. A proposta política de um município para a inclusão escolar: um tema, vários olhares. 01/12/2005 
1v. 178p. Doutorado. UNIVERSIDADE FEDERAL DE SÃO CARLOS - EDUCAÇÃO

Orientador(es): Aline Maria de Medeiros Rodrigues Reali

Biblioteca Depositária: Biblioteca Comunitária da UFSCar

7. Rosimeire Maria Orlando Zeppone. A inclusão escolar de crianças deficientes e a prática docente. 01/02/2005

1v. 231p. Doutorado. UNIVERSIDADE EST. PAULISTA JÚLIO DE MESQUITA FILHO/ARARAQUARA educação escolar

Orientador(es): Alda Junqueira Marin

Biblioteca Depositária: FCL/Ar-UNESP

8. Hildete Pereira dos Anjos. O Espelho em Cacos: Uma leitura em reconhecimento dos discursos em embate no campo da inclusão. 01/12/2006

1v. 324p. Doutorado. UNIVERSIDADE FEDERAL DA BAHIA - EDUCAÇÃO

Orientador(es): Theresinha Guimarães Miranda

Biblioteca Depositária: Biblioteca Anísio Teixeira - FACED e Biblioteca Central da UFB

9. Roberta Galasso Nardi. Ressignificando a educação especial a partir da complexidade e do pensamento ecossistêmico. 01/06/2007

1v. 198p. Doutorado. PONTIFÍCIA UNIVERSIDADE CATÓLICA DE SÃO PAULO - educação (currículo)

Orientador(es): Maria Candida Borges de Moraes

Biblioteca Depositária: PUC/SP

10. Joslei Viana de Souza. Tutoria: estratégias de ensino para inclusão de alunos com deficiência em aulas de Educação Física. 01/02/2008

2v. 136p. Doutorado. UNIVERSIDADE FEDERAL DE SÃO CARLOS - educação especial (educação do indivíduo especial)

Orientador(es): Maria da Piedade Resende da Costa

Biblioteca Depositária: Biblioteca Comunitária da UFSCar

11. Andrea Regina Rosin Pinola. Programa de habilidades sociais educativas: impacto sobre 0 repertório de professores e de alunos com necessidades educacionais especiais. 01/12/2009

1v. 216p. Doutorado. UNIVERSIDADE DE SÃO PAULO / RIBEIRÃO PRETO - PSICOLOGIA

Orientador(es): Zilda Aparecida Pereira Del Prette

Biblioteca Depositária: Ribeirão Preto

12. Andressa Mafezoni Caetano. A formação inicial de professores na perspectiva da inclusão escolar de alunos com deficiência: o curso de pedagogia da Universidade Federal do Espírito Santo. 01/07/2009

1v. 238p. Doutorado. UNIVERSIDADE FEDERAL DO ESPÍRITO SANTO - EDUCAÇÃO

Orientador(es): Denise Meyrelles de Jesus

Biblioteca Depositária: Biblioteca da UFES

13. Marli Vizim. Avanços e impasses nas políticas públicas de inclusão: o centro de atenção à inclusão social de Diadema. 01/03/2009

1v. 221p. Doutorado. UNIVERSIDADE DE SÃO PAULO - EDUCAÇÃO

Orientador(es): Lisete Regina Gomes Arelaro 
Biblioteca Depositária: FEUSP

14. Remi Fernand Lavergne. A vontade de incluir: regime de verdade, recomposição das práticas e estratégias de apropriação a partir de um dispositivo de inclusão escolar em Fortaleza. 01/07/2009 1v. 413p. Doutorado. UNIVERSIDADE FEDERAL DO CEARÁ - EDUCAÇÃO

Orientador(es): Rita Vieira de Figueiredo

Biblioteca Depositária: Biblioteca de Ciências Humanas

15. Bianca Fátima Cordeiro dos Santos Fogli. A Dialética da inclusão em educação: uma possibilidade num cenário de contradições - Um estudo de caso sobre a implementação da política de inclusão para alunos com deficiências na rede de ensino Faetec. 01/12/2010 1v. 120p. Doutorado. UNIVERSIDADE DO ESTADO DO RIO DE JANEIRO - EDUCAÇÃO

Orientador(es): Rosana Glat

Biblioteca Depositária: UERJ/REDE SIRIUS/BIBLIOTECA CEH-A

16. Douglas Roberto Borella. Atividade física adaptada no contexto das matrizes curriculares dos cursos de educação física. 01/11/2010

1v. 164p. Doutorado. UNIVERSIDADE FEDERAL DE SÃO CARLOS - EDUCAÇÃO ESPECIAL (educação do indivíduo especial).

Orientador(es): Fátima Elisabeth Denari

Biblioteca Depositária: Biblioteca Digital de Teses e Dissertações - BCo/UFSCar

17. Mariangela Lima de Almeida. Uma análise da produção acadêmica sobre os usos da pesquisaação em processos de inclusão escolar: entre o agir comunicativo e o agir estratégico. 01/04/2010. 1v. 233p. Doutorado. UNIVERSIDADE FEDERAL DO ESPÍRITO SANTO - EDUCAÇÃO.

Orientador(es): Denise Meyrelles de Jesus

Biblioteca Depositária: Biblioteca da UFES

18. Claudio Roberto Machado Benite. Formação do professor e docência em química em rede social: estudos sobre inclusão escolar e o pensar comunicativo. 01/12/2011

1v. 200p. Doutorado. UNIVERSIDADE FEDERAL DE GOIÁS - QUÍMICA

Orientador(es): Anna Maria Canavarro Benite

Biblioteca Depositária: Biblioteca da UFG

19. Ines de Oliveira Ramos Martins. Educação especial e a superintendência regional de educação de Cariacica: um diálogo possível. 01/11/2011

1v. 245p. Doutorado. UNIVERSIDADE FEDERAL DO ESPÍRITO SANTO - EDUCAÇÃO

Orientador(es): Denise Meyrelles de Jesus

Biblioteca Depositária: Biblioteca Central da UFES

20. Maria de Lourdes Esteves Bezerra. Inclusão de pessoas com deficiência visual na escola regular: bases organizativas e pedagógicas no estado do Acre. 01/02/2011

1v. 256p. Doutorado. UNIVERSIDADE FEDERAL DE MINAS GERAIS - EDUCAÇÃO

Orientador(es): Aracy Alves Martins

Biblioteca Depositária: Biblioteca da Faculdade de Educação 


\section{Teses selecionadas a partir da expressão exata educação inclusiva.}

21. Rita de Cassia Barbosa Paiva Magalhães. Ditos e feitos da educação inclusiva: navegações pelo currículo escolar. 01/03/2005

1v. 260p. Doutorado. UNIVERSIDADE FEDERAL DO CEARÁ - educação

Orientador(es): Ana Maria lório Dias

Biblioteca Depositária: HUMANIDADES/UFC

22. Simone Girardi Andrade. Ação docente, formação continuada e inclusão escolar. 01/09/2005

1v. 205p. Doutorado. UNIVERSIDADE FEDERAL DO RIO GRANDE DO SUL - educação

Orientador(es): Claudio Roberto Baptista

Biblioteca Depositária: Biblioteca Setorial de Educação

23. Adriano Monteiro de Castro. A avaliação da aprendizagem no contexto da inclusão de alunos com necessidades educacionais especiais na escola pública. 01/04/2007

1v. 295p. Doutorado. UNIVERSIDADE DE SÃO PAULO - educação

Orientador(es): Roseli Cecilia Rocha de Carvalho Baumel

Biblioteca Depositária: FEUSP

24. Agda Felipe Silva Gonçalves. As políticas públicas e a formação continuada de professores na implementação da inclusão escolar no município de Cariacica. 01/02/2008

1v. 355p. Doutorado. UNIVERSIDADE FEDERAL DO ESPÍRITO SANTO - educação

Orientador(es): Denise Meyrelles de Jesus

Biblioteca Depositária: Biblioteca da UFES

25. Esther Giacomini Silva. O perfil docente para a educação inclusiva - uma análise das atitudes, habilidades sociais e o perfil escolar inclusivo. 01/02/2008

1v. 132p. Doutorado. UNIVERSIDADE EST. PAULISTA JÚLIO DE MESQUITA FILHO/MARÍLIA educação

Orientador(es): Sadao Omote

Biblioteca Depositária: UNIVERSIDADE ESTADUAL PAULISTA - MARÍLIA

26. Maria Aparecida de Menezes. Formação de professores de alunos com necessidades educacionais especiais no ensino regular. 01/05/2008

1v. 250p. Doutorado. PONTIFÍCIA UNIVERSIDADE CATÓLICA DE SÃO PAULO - educação (currículo) Orientador(es): Marina Graziela Feldmann

Biblioteca Depositária: PUC-SP

27. Amélia Rota Borges de Bastos. Sendero inclusivo: o caminho da escola peregrina na inclusão de alunos com necessidades educacionais especiais. 01/09/2009

1v. 138p. Doutorado. UNIVERSIDADE DO VALE DO RIO DOS SINOS - educação

Orientador(es): Maria Isabel da Cunha

Biblioteca Depositária: Universidade do Vale do Rio dos Sinos - UNISINOS

28. Carlos César Barros. Fundamentos filosóficos e políticos da inclusão escolar: um estudo sobre a subjetividade docente. 01/05/2009 
1v. 260p. Doutorado. UNIVERSIDADE DE SÃO PAULO - psicologia escolar e do desenvolvimento humano

Orientador(es): Iray Carone

Biblioteca Depositária: IP

29. Deigles Giacomelli Amaro. Análise de procedimentos utilizados em uma proposta de formação contínua de educadores em serviço para a construção de práticas inclusivas. 01/04/2009

1v. 257p. Doutorado. UNIVERSIDADE DE SÃO PAULO - educação

Orientador(es): Leny Magalhães Mrech

Biblioteca Depositária: FEUSP

30. Francisca Geny Lustosa. Inclusão, o olhar que ensina: o movimento da mudança e a transformação das práticas pedagógicas no contexto de uma pesquisa-ação. 01/04/2009

1v. 275p. Doutorado. UNIVERSIDADE FEDERAL DO CEARÁ - educação

Orientador(es): Rita Vieira de Figueiredo

Biblioteca Depositária: Biblioteca de Ciências Humanas

31. Iara Maria Campelo Lima. Tecendo saberes, dizeres, fazeres em formação contínua de professores: uma perspectiva de educação inclusiva. 01/04/2009

1v. 277p. Doutorado. UNIVERSIDADE FEDERAL DA BAHIA - educação

Orientador(es): Theresinha Guimarães Miranda

Biblioteca Depositária: Anísio Teixeira - FACED/UFBA

32. Josiane Pozzatti Dal-Forno. Formação de formadores e educação inclusiva: análise de uma experiência via internet. 01/12/2009

1v. 303p. Doutorado. UNIVERSIDADE FEDERAL DE SÃO CARLOS - educação

Orientador(es): Aline Maria de Medeiros Rodrigues Reali

Biblioteca Depositária: Biblioteca Digital de Teses e Dissertações - BCo/UFSCar

33. Sonia Maria Ribeiro. O esporte adaptado e a inclusão de alunos com deficiências nas aulas de educação física. 01/08/2009

1v. 100p. Doutorado. UNIVERSIDADE METODISTA DE PIRACICABA - educação

Orientador(es): Maria Cecília Carareto Ferreira

Biblioteca Depositária: Taquaral/UNIMEP; INEP

34. Gabriela Souza de Melo Mieto. Virtuosidade em professores de inclusão escolar de crianças com deficiência intelectual. 01/08/2010

1v. 160p. Doutorado. UNIVERSIDADE DE BRASÍLIA - processos de desenvolvimento humano e saúde

Orientador(es): Silviane Bonaccorsi Barbato

Biblioteca Depositária: UnB

35. Cristina Façanha Soares. As diferenças no contexto da educação infantil: um estudo da prática pedagógica. 01/10/2011

1v. 278p. Doutorado. UNIVERSIDADE FEDERAL DO CEARÁ - educação

Orientador(es): Rita Vieira de Figueiredo

Biblioteca Depositária: Biblioteca de Ciências Humanas 
36. João Danilo Batista de Oliveira. A educação física especial e currículo: (in)formação para a educação inclusiva. 01/07/2011

1v. 307p. Doutorado. UNIVERSIDADE FEDERAL DA BAHIA - educação

Orientador(es): Roberto Sanches Rabêllo

Biblioteca Depositária: Biblioteca Anísio Teixeira

37. Viviane Preichardt Duek. Educação inclusiva e formação continuada: contribuições dos casos de ensino para os processos de aprendizagem e desenvolvimento profissional de professores. 01/02/2011

1v. 349p. Doutorado. UNIVERSIDADE FEDERAL DO RIO GRANDE DO NORTE - educação

Orientador(es): Lúcia de Araújo Ramos Martins

Biblioteca Depositária: Biblioteca Central Zila Mamede - UFRN

Teses selecionadas a partir das duas expressões exatas: educação especial e educação inclusiva.

38. Maria Angélica do Carmo Zanotto (D). A formação contínua como possibilidade do aprimoramento da ação de problematizar: análise de uma proposta voltada para professores atuantes em educação especial. 01/03/2002

1v. 112p. Doutorado. UNIVERSIDADE FEDERAL DE SÃO CARLOS - educação especial (educação do indivíduo especial)

Orientador(es): Julio Cesar Coelho de Rose

Biblioteca Depositária: Biblioteca Comunitária da UFSCar

39. Maria Julia Lemes Ribeiro. Formação de professores: conhecendo as formas de organização curricular das especializações e as necessidades do professor para a prática de uma educação inclusiva. 01/02/2005

1v. 242p. Doutorado. UNIVERSIDADE DE SÃO PAULO - educação

Orientador(es): Roseli Cecilia Rocha de Carvalho Baumel

Biblioteca Depositária: FEUSP

40. Haydea Maria Marino de Sant'Anna Reis. Educação Inclusiva é para todos? A (falta de) formação docente para Altas Habilidades/ Superdotação no Brasil. 01/03/2006

2v. 267p. Doutorado. UNIVERSIDADE DO ESTADO DO RIO DE JANEIRO - educação

Orientador(es): Marsyl Bulkool Metrau

Biblioteca Depositária: Faculdade de Educação da UERJ

41. Luzia de Fatima Medeiros de Oliveira. Apoio pedagógico, ação coletiva e diálogo: trama da formação continuada em educação inclusiva. 01/11/2006

1v. 250p. Doutorado. UNIVERSIDADE FEDERAL DO RIO GRANDE DO NORTE - educação

Orientador(es): Ana Lúcia Assunção Aragão

Biblioteca Depositária: Biblioteca setorial do CCSA

42. Antonia Maria Nakayama. Educação inclusiva: princípios e representação. 01/11/2007

1v. 355p. Doutorado. UNIVERSIDADE DE SÃO PAULO - educação

Orientador(es): Roseli Cecilia Rocha de Carvalho Baumel

Biblioteca Depositária: FEUSP 
43. Rejane de Souza Fontes. A educação inclusiva no município de Niterói (RJ): das propostas oficiais às experiências em sala de aula - o desafio da bidocência. 01/10/2007

1v. 210p. Doutorado. UNIVERSIDADE DO ESTADO DO RIO DE JANEIRO - educação

Orientador(es): Rosana Glat

Biblioteca Depositária: UERJ

44. Lázara Cristina da Silva. Políticas públicas e formação de professores: vozes e vieses da educação inclusiva. 01/05/2009

1v. 344p. Doutorado. UNIVERSIDADE FEDERAL DE UBERLÂNDIA - educação

Orientador(es): Marilúcia de Menezes Rodrigues

Biblioteca Depositária: Universidade Federal de Uberlândia

45. Niedja Maria Ferreira de Lima. Programa educação inclusiva: direito à diversidade no Município-polo de Campina Grande/PB - da política oficial à prática explicitada. 01/07/2009

1v. 301p. Doutorado. UNIVERSIDADE FEDERAL DA PARAÍBA/JOÃO PESSOA - educação

Orientador(es): Ana Dorziat Barbosa de Melo

Biblioteca Depositária: Biblioteca Central da UFPB/Biblioteca Setorial do CE

46. Cristiane Regina Xavier Fonseca-Janes. A formação dos estudantes de pedagogia para a educação inclusiva: estudo das atitudes sociais e do currículo. 01/11/2010

1v. 269p. Doutorado. UNIVERSIDADE EST. PAULISTA JÚLIO DE MESQUITA FILHO/MARÍLIA educação

Orientador(es): Sadao Omote

Biblioteca Depositária: Faculdade de Filosofia e Ciências

47. Marlene Rozek. Histórias de vida de professoras da educação especial: subjetividade e formação. 01/01/2010

1v. 178p. Doutorado. UNIVERSIDADE FEDERAL DO RIO GRANDE DO SUL - educação

Orientador(es): Claudio Roberto Baptista

Biblioteca Depositária: Biblioteca Setorial de Educação

48. Helio Ferreira Orrico. A inclusão educacional de alunos com necessidades educacionais especiais frente ao aspecto atitudinal do corpo docente nos primeiros e sextos anos do ensino fundamental. 01/02/2011

1v. 114p. Doutorado. UNIVERSIDADE EST. PAULISTA JÚLIO DE MESQUITA FILHO/MARÍLIA educação

Orientador(es): Sadao Omote

Biblioteca Depositária: Faculdade de Filosofia e Ciências

49. Katia Regina de Oliveira Rios Pereira Santos. Formação continuada (em serviço) e necessidades formativas de professores na educação de surdos da rede pública da cidade do Rio de Janeiro. 01/06/2011

1v. 100p. Doutorado. UNIVERSIDADE METODISTA DE PIRACICABA - educação

Orientador(es): Cristina Broglia Feitosa de Lacerda

Biblioteca Depositária: Biblioteca Taquaral 
50. Sandra Salete de Camargo Silva. Políticas educacionais pós-1990: o contexto da inclusão e a formação dos profissionais da educação infantil. 01/03/2011

1v. 219p. Doutorado. UNIVERSIDADE ESTADUAL DE MARINGÁ - educação

Orientador(es): Aurea Maria Paes Leme Goulart

Biblioteca Depositária: BCE - Biblioteca Central da UEM 